\title{
MODELLING OF NON-CATALYTIC REACTIONS IN A GAS-SOLID TRICKLE FLOW REACTOR: DRY, REGENERATIVE FLUE GAS DESULPHURISATION USING A SILICA-SUPPORTED COPPER OXIDE SORBENT
}

\author{
J. H. A. KIEL, ${ }^{\dagger}$ W. PRINS and W. P. M. VAN SWAAIJ \\ Department of Chemical Engineering. University of Twente, PO Box 217, 7500 AE Enschede, \\ The Netherlands
}

(Received 20 December 1991; accepted 31 March 1992)

\begin{abstract}
A one-dimensional, two-phase axially dispersed plug flow model has been developed to describe the steady-state performance of a relatively new type of reactor, the gas-solid trickle flow reactor (GSTFR). In this reactor, an upward-flowing gas phase is contacted with a downward-flowing dilute solids phase over an inert packing. The model is derived from the separate mass and heat balances for both the gas and (porous) solids phases for the case of a non-catalytic gas-solid reaction, which is first-order in the gaseous reactant. The reaction rate may also depend on the solid reactant concentration, but this concentration is assumed to be low and uniform throughout the solids volume. From the model, axial profiles can be calculated numerically for the four independent variables, viz, the gas-phase and solids-phase temperatures and the concentrations of the gaseous and solid reactant. Under isothermal conditions, the model equations can be solved analytically; the resulting expressions for the axial profiles of the gaseous and solid reactant are presented. The model is applied to predict the flue gas desulphurisation performance of a full-scale GSTF absorber in a dry, regenerative process for the simultaneous removal of $\mathrm{SO}_{\boldsymbol{x}}$ and $\mathrm{NO}_{\boldsymbol{x}}$ from flue gases. In this process, to be operated at $350-400^{\circ} \mathrm{C}$, the sorbent material consists of a porous silica support (spherical particles, $1.5 \mathrm{~mm}$ diameter) with $7.5 \mathrm{wt} \%$ CuO deposited on this support by an ion-exchange technique. The model calculations are based on experimental findings from previous studies regarding reaction kinetics, hydrodynamics of the two-phase flow, gas-solids mass transfer and testing of the integrated process in a bench-scale plant. It appears that $\mathrm{SO}_{2}$ removal efficiencies over $95 \%$ can be achieved in a GSTF absorber with a length of $15 \mathrm{~m}$. Furthermore, the model predicts a large temperature peak for both phases in the absorber if the heat capacity ratio (defined as the ratio of mass flux times specific heat capacity for both phases) is close to one. This large temperature peak is due to the occurrence of the exothermic reaction of $\mathrm{SO}_{2}$ with $\mathrm{CuO}$ in combination with efficient counter-current gas-solids heat exchange. Several parameters influencing the magnitude and axial position of the maximum gas-phase and solids-phase temperatures are discussed.
\end{abstract}

\section{INTRODUCTION}

Gas-solid trickle flow is characterised by countercurrent flow of gas and a dilute phase of solid particles over a packed column. Previous studies showed several favourable properties of gas-solid trickle flow such as a low pressure drop, little axial mixing in both phases and high rates of gas-solids heat and mass transfer (Roes and van Swaaij, 1979b; Verver and van Swaaij, 1986b). Until now, industrial applications were aimed at heat recovery from gases and particulate solids (Guigon et al., 1986). However, several studies on a laboratory scale showed the potential of gas-solid trickle flow for adsorption and chemical reactions as well (Kuczynski, 1986; Verver and van Swaaij, 1987).

The packing in a gas-solid trickle flow reactor (GSTFR) may consist of randomly dumped Pall or Raschig rings, as they are used in gas-liquid trickle flow, but Large et al. (1983) showed that with these packings it is quite difficult to achieve a good radial distribution of the solids over the cross-sectional area of the column. Verver and van Swaaij (1986a) and Kiel (1990) studied the application of several regularly

'Present address: Netherlands Energy Research Foundation ECN, PO Box 1, 1755 ZG Petten, The Netherlands. stacked packings, built up of bars (or tubes) with a circular or square cross-section. They found that, if well-designed, the regularly stacked packing itself induces a good radial (re-)distribution of both the phases, avoiding the need of a good initial distribution by the solids distributor. Moreover, by applying regularly stacked packings a substantially lower pressure drop and static solids hold-up, i.e. solid particles staying permanently in the column, could be achieved.

Recently, we investigated the application of a GSTFR, with a regularly stacked packing, as the absorber in a continuous dry regenerative process for the simultaneous removal of $\mathrm{SO}_{x}$ and $\mathrm{NO}_{x}$ from flue gases. Copper oxide (CuO) on a porous silica support (spherical particles, $1.5 \mathrm{~mm}$ diameter) is used as the sorbent material. In the GSTF absorber, $\mathrm{SO}_{\boldsymbol{x}}$ reacts with the supported $\mathrm{CuO}$ to form copper sulphate $\left(\mathrm{CuSO}_{4}\right)$ at $300-450^{\circ} \mathrm{C}$. Simultaneously, both $\mathrm{CuO}$ and $\mathrm{CuSO}_{4}$ act as catalysts for the selective catalytic reduction of $\mathrm{NO}_{x}$ with ammonia $\left(\mathrm{NH}_{3}\right)$. Regeneration of the sulphated sorbent is carried out with a reducing gas, e.g. hydrogen, at the same temperature as the absorption, the $\mathrm{CuSO}_{4}$ being reduced to metallic copper. The regenerator off-gas is rich in $\mathrm{SO}_{2}$ and can be further processed to produce sulphuric acid or elemental sulphur. The reduced sorbent can be oxidised and used for $\mathrm{SO}_{x}$ absorption again. 
If compared to the widely used limestone scrubbing for flue gas desulphurisation, this process based on $\mathrm{CuO}$ offers the advantages of (i) a small sorbent makeup, (ii) producing only a relatively small amount of saleable by-product, (iii) avoiding stack gas reheat and a large water consumption and (iv) the possibility of simultaneous $\mathrm{NO}_{x}$ removal. By applying a GSTFR as the absorber instead of a modified fixed bed, a fluidised bed or a moving bed, which were used in previously developed CuO processes (Dautzenberg et al., 1971; Ploeg, 1981; Yeh et al., 1985; Stelman et al., 1987), it becomes possible to combine continuous operation with a low pressure drop for the flue gas. To limit the required cross-sectional area of the absorber, relatively large sorbent particles (millimetre-sized) are to be preferred since they allow a high superficial flue gas velocity. Furthermore, the good (re-)distribution property of the specially designed regularly stacked packings is very advantageous given the large size of the absorber due to the large flue gas quantities to be processed in the case of oil- or coal-fired eleetric power plants.

In several previous articles, results have been reported of detailed experimental studies on specific aspects of the new flue gas treating process, viz. (i) reaction kinetics of $\mathbf{S O}_{x}$ removal and sorbent regeneration (Kiel et al., 1992a), (ii) reaction kinetics of selective catalytic $\mathrm{NO}_{x}$ removal (Kiel et al., 1992b) and (iii) hydrodynamics of gas-solid trickle flow over regularly stacked packings using coarse particles (Kiel and van Swaaij, 1989; Kiel, 1990). Furthermore, results have been presented obtained from experiments carried out in a bench-scale plant consisting of a GSTF absorber with a limited reactor length of $1.06 \mathrm{~m}$, a fluidised-bed regenerator and a pneumatic transport system for continuous sorbent circulation (Kiel et al., 1990). These bench-scale experiments were confined to flue gas desulphurisation; $\mathrm{NO}_{x}$ removal was not yet taken into account.

Based on the experimental results presented previously, in this article the flue gas desulphurisation performance of a GSTF absorber in a full-scale plant will be predicted using a onc-dimensional, two-phase axially dispersed plug flow model. The model is an extended version of the straightforward one-dimensional two-phase plug flow model, which was introduced earlier (Kiel et al., 1990) to describe the performance of the GSTF absorber in the bench-scale plant. In the present model, axial dispersion and nonisothermal behaviour are included.

In the next section, the model will be derived for the general case of a non-catalytic gas -solid reaction, which is first-order in the gaseous reactant. A possible dependence of the intrinsic reaction rate on the concentration of solid reactant is taken into account to a limited extent. The resulting mass and heat balances form a set of four coupled non-linear second-order differential equations. From the related boundary conditions, the problem may be characterised as a two-point boundary value problem, which has to be solved numerically to yield axial temperature profiles for both phases and axial concentration profiles for the gaseous and solid reactant. If the problem is simplified by assuming (i) isothermal conditions and (ii) the reaction rate to be independent of the concentration of solid reactant, then the two remaining mass balances can be solved analytically. The resulting expressions for the axial concentration profiles of the gaseous reactant in the gas phase and the solid reactant in the solids phase are presented.

The flue gas desulphurisation performance of a fullscale GSTF absorber in a $\mathrm{CuO}$ process for the simultaneous removal of $\mathrm{SO}_{x}$ and $\mathrm{NO}_{x}$ from flue gases is discussed in subsequent sections. First, axial concentration and temperature profiles are presented for base case conditions, which were derived from experimental findings. Then the influence of the individual process parameters on the performance of the GSTF absorber is discussed.

\section{MODEL DEVELOPMENT}

\subsection{Basic equations}

The model was developed for a non-catalytic gas-solid reaction taking place in a gas-solid trickle flow reactor (GSTFR). It is based on the following assumptions:

- The gas-solids system is at steady state.

- There are no radial concentration and temperature gradients in the column (one-dimensional model).

- The volumetric flow rate of the gas phase is constant over the column length (constant gas density).

- The packing porosity and the (dynamic) solids hold-up are constant over the column length.

- The particles are spherical and uniform in size and density.

- Intraparticle temperature gradients are negligible.

- Gas-solids heat transfer via the packing, solidsto-column wall heat transfer, and radiation are negligible.

The reaction is first-order in the gaseous reactant and the concentration of gaseous reactant is low.

- The reaction rate may depend on the solid reactant concentration, but this concentration is supposed to be low and uniform over the particle volume.

The assumption of negligible radial concentration and temperature gradients in the column does not seriously restrict the applicability of the model; the specially designed regularly stacked packings induce a good radial (re-)distribution of both phases. For a certain application, a criterion derived by Anderson (1963) can be applied to determine whether it is allowed to neglect intraparticle temperature gradients. The assumption of negligible gas-solids heat transfer via the packing, solids-to-column wall heat transfer, and radiation in the heat balance is based on the experimental findings presented by Verver and van 
Swaaij (1986b). They investigated the heat-transfer performance of gas-solid trickle flow over regularly stacked packings using $370 \mu \mathrm{m}$ diameter sand particles for the solids phase while using air for the gas phase. The last-mentioned assumption, stating that the solid reactant concentration is independent of the radial position inside the solid particles, is a restricting one, if the influence of pore diffusion on the overall reaction rate is considerable compared to the influence of reaction kinetics.

Generally, in a GSTFR, deviations from plug flow will be small in both phases due to the presence of the regularly stacked packing. Therefore, axial mixing is taken into account by introducing longitudinal dispersion terms into the mass and heat balances. All possible deviations from plug flow, such as velocity differences, eddies and vortices, are then lumped in the values of the effective longitudinal dispersion coefficients for mass $\left(D_{l}\right)$ and heat $\left(\lambda_{t}\right)$ [axially dispersed plug flow model, see e.g. Westerterp et al. (1984)]. Taking the axial coordinate $z$ to be positive in the upward direction, the mass and heat balances for both phases can then be expressed as

Mass balance for the gaseous reactant over the gas phase:

$$
(\varepsilon-\bar{\beta}) D_{l g} \frac{\mathrm{d}^{2} C_{g}}{\mathrm{~d} z^{2}}-\frac{G}{\rho_{g 0}} \frac{\mathrm{d} C_{g}}{\mathrm{~d} z}-k_{g} a\left(C_{g}-C_{g i}\right)=0
$$

Mass balance for the solid reactant (over the solids phase):

$$
\bar{\beta} D_{l s} \frac{\mathrm{d}^{2} C_{s}}{\mathrm{~d} z^{2}}+\frac{S}{\rho_{s}} \frac{\mathrm{d} C_{s}}{\mathrm{~d} z}-v k_{s} a\left(C_{g}-C_{g i}\right)=0
$$

Heat balance over the gas phase:

$$
\begin{aligned}
(\varepsilon-\bar{\beta}) \lambda_{l g} \frac{\mathrm{d}^{2} T_{g}}{\mathrm{~d} z^{2}}-G c_{p g} \frac{\mathrm{d} T_{g}}{\mathrm{~d} z}-\alpha a\left(T_{g}-T_{s}\right) \\
-\frac{4 \alpha_{\mathrm{w}}}{b}\left(T_{g}-T_{\mathrm{amb}}\right)=0
\end{aligned}
$$

Heat balance over the solids phase:

$$
\begin{aligned}
\bar{\beta} \lambda_{l s} \frac{\mathrm{d}^{2} T_{s}}{\mathrm{~d} z^{2}}+S c_{p \times} \frac{\mathrm{d} T_{s}}{\mathrm{~d} z}+\alpha a\left(T_{g}-T_{s}\right) \\
+(-\Delta H) v k_{g} a\left(C_{g}-C_{g i}\right)=0 .
\end{aligned}
$$

To eliminate the unknown interface concentration, $C_{a t}$, from eqs (1)-(4), an additional equation, the mass balance for the gaseous reactant over the porous solids phase, will be introduced:

$$
k_{g} a\left(C_{g}-C_{g i}\right)=\bar{\beta} \eta k_{r}^{*} C_{g i} \text {. }
$$

The possible influence of pore diffusion is included by means of the effectiveness factor, $\eta$. $k_{r}^{*}$ represents an effective intrinsic reaction rate constant, which includes a possible influence of the solid reactant conversion degree on the intrinsic reaction rate. For a gas-solid reaction, which is first-order in the gaseous reactant, and in the case of spherical particles, the effectiveness factor, $\eta$, is related to the Thiele modulus, $\phi$, defined as $\phi=d_{s} / 6\left(k_{r}^{*} / D_{\text {.ff }}\right)^{0.5}$, according to [see e.g. Froment and Bischoff (1979)]

$$
\eta=\frac{1}{\phi}\left(\frac{1}{\tanh (3 \phi)}-\frac{1}{3 \phi}\right)
$$

$D_{\text {eff }}$ is the effective diffusion coefficient of the gaseous reactant in the pores of the solid particles, which is mostly unknown. Since the concentration of the solid reactant is assumed to be low, changes of the pore structure can be neglected. Moreover, pore diffusion can be regarded as equimolar counterdiffusion because also the (intraparticle) concentration of the gaseous reactant is assumed to be low. Consequently, the effective diffusion coefficient can be taken as constant and estimated by [see e.g. Satterfield (1970)]

$$
\frac{1}{D_{\text {eff }}}=\frac{\tau}{\varepsilon_{s}}\left(\frac{1}{D_{A}}+\frac{1}{D_{K}}\right)
$$

where $D_{A}$ is the molecular diffusion coefficient, $D_{K}$ the Knudsen diffusion coefficient and $\varepsilon_{s}$ the particle porosity. $\tau$ represents the tortuosity factor of the pores. If this tortuosity factor is unknown, it can be approximated by relating it to the particle porosity according to $\tau=1 / \varepsilon_{s}$ [see e.g. Satterfield (1970)].

Gas-solids mass transfer and pore diffusion plus reaction kinetics can be treated as two resistances in series by defining an overall rate constant $k_{o v}$ as

$$
\frac{1}{k_{o v}}=\frac{1}{k_{g} a}+\frac{1}{\bar{\beta} \eta k_{r}^{*}}
$$

Using eqs (5) and (8) to eliminate $C_{o i}$, and introducing $Z=z / L, \quad x_{\theta}=1-C_{g} / C_{\theta 0}, \quad x_{s}=1-C_{s} / C_{s 0}$, $\vartheta_{g}=T_{g} / T_{g 0}$ and $\vartheta_{s}=T_{s} / T_{g 0}$, the set of four basic model equations [eqs (1)-(4)] can be rewritten in the following dimensionless way:

$$
\begin{gathered}
\frac{1}{P e_{m g}} \frac{\mathrm{d}^{2} x_{g}}{\mathrm{~d} Z^{2}}-\frac{\mathrm{d} x_{g}}{\mathrm{~d} Z}+N_{m g}\left(1-x_{g}\right)=0 \\
\frac{1}{P e_{m s}} \frac{\mathrm{d}^{2} x_{s}}{\mathrm{~d} Z^{2}}+\frac{\mathrm{d} x_{s}}{\mathrm{~d} Z}+N_{m s}\left(1-x_{g}\right)=0 \\
\frac{1}{P e_{h g}} \frac{\mathrm{d}^{2} \vartheta_{g}}{\mathrm{~d} Z^{2}}-\frac{\mathrm{d} \vartheta_{g}}{\mathrm{~d} Z}-N_{h g}\left(\vartheta_{g}-\vartheta_{s}\right) \\
-N_{h w}\left(\vartheta_{g}-\vartheta_{\mathrm{amb}}\right)=0 \\
\frac{1}{P e_{h s}} \frac{\mathrm{d}^{2} \vartheta_{s}}{\mathrm{~d} Z^{2}}+\frac{\mathrm{d} \vartheta_{s}}{\mathrm{~d} Z}+N_{h s}\left(\vartheta_{g}-\vartheta_{s}\right)+N_{h r}\left(1-x_{g}\right)=0
\end{gathered}
$$

$T_{g 0}$ represents the gas inlet temperature, $C_{g 0}$ the inlet concentration of gaseous reactant in the gas phase, and $C_{s a}$ the inlet concentration of solid reactant in the solids phase. The significance of the dimensionless groups in eqs (9)-(12) is

$$
\begin{gathered}
P e_{m g}=\frac{G L}{(\varepsilon-\bar{\beta}) \rho_{g o} D_{l \theta}}, \quad P e_{m s}=\frac{S L}{\bar{\beta} \rho_{s} D_{l s}} \\
P e_{k g}=\frac{G c_{p g} L}{(\varepsilon-\bar{\beta}) \lambda_{l g}}, \quad P e_{h s}=\frac{S c_{p s} L}{\bar{\beta} \lambda_{l s}}
\end{gathered}
$$




$$
\begin{gathered}
N_{m g}=\frac{\rho_{g 0} k_{o v} L}{G}, \quad N_{m s}=\frac{\rho_{s} v k_{o v} L C_{g 0}}{S C_{s 0}} \\
N_{h g}=\frac{\alpha a L}{G c_{p g}}, \quad N_{h s}=\frac{\alpha a L}{S c_{p s}} \\
N_{h w}=\frac{4 \alpha_{w} L}{b G c_{p g}}, \quad N_{h r}=\frac{(-\Delta H) v k_{o v} L C_{g 0}}{S c_{p s} T_{g 0}} .
\end{gathered}
$$

For both the gas and solids phase, the boundaries are taken as closed for dispersion at the inlet and outlet of the gas-solid trickle flow reactor, which results in the well-known Danckwerts equations (Danckwerts, 1953):

At $\mathcal{Z}=0$ :

$$
\begin{gathered}
\frac{\mathrm{d} x_{\theta}}{\mathrm{d} Z}=P e_{m \theta} x_{\theta}, \quad \frac{\mathrm{d} x_{s}}{\mathrm{~d} Z}=0 \\
\frac{\mathrm{d} \vartheta_{g}}{\mathrm{~d} Z}=P e_{h \theta}\left(\vartheta_{\theta}-1\right), \quad \frac{\mathrm{d} \vartheta_{s}}{\mathrm{~d} Z}=0 .
\end{gathered}
$$

At $Z=1$ :

$$
\begin{gathered}
\frac{\mathrm{d} x_{g}}{\mathrm{~d} Z}=0, \quad \frac{\mathrm{d} x_{s}}{\mathrm{~d} Z}=-P e_{m s} x_{s} \\
\frac{\mathrm{d} \vartheta_{g}}{\mathrm{~d} Z}=0, \quad \frac{\mathrm{d} \vartheta_{s}}{\mathrm{~d} Z}=P e_{h s}\left(1-\vartheta_{s}\right) .
\end{gathered}
$$

Equations (9)-(12) form a set of four coupled nonlinear second-order differential equations with the following four independent variables: $x_{g}$, the fractional conversion of gaseous reactant in the gas phase; $x_{s}$, the fractional conversion of solid reactant; $\vartheta_{g}$, the dimensionless temperature of the gas phase; and $\vartheta_{s}$, the dimensionless temperature of the solids phase. Furthermore, since boundary conditions have to be satisfied at $Z=0$ and $Z=1$, the problem may be characterised mathematically as a two-point boundary value problem.

\subsection{Analytical solution (isothermal conditions)}

Generally, the set of four coupled non-linear second-order differential equations (9)-(12) has to be solved numerically. However, analytical solutions can be derived for the axial concentration profiles of the gaseous and solid reactant if the reactor is assumed to be isothermal and if the intrinsic reaction rate is assumed to be independent of the concentration of solid reactant. In that case, the dimensionless mass balance for the gaseous reactant in the gas phase [eq. (9)] has only one unknown variable, viz. the fractional conversion of the gaseous reactant in the gas phase, $x_{g}$, and can, therefore, be solved separately. The following solution for $x_{a}$ as a function of the dimensionless axial position, $\mathcal{Z}$, was already given by Danckwerts (1953) and by Wehner and Wilhelm (1956): where $p=P e_{m g} / 2$ and $q=\sqrt{1+4 N_{m g} / P e_{m g}}$. Using this solutions for $x_{g}$, the following expression can be derived for the fractional conversion of solid reactant, $x_{s}$ :

$$
\begin{aligned}
x_{s}= & \frac{N_{m s}}{\operatorname{denom} .}\left\{\frac{1}{p} \exp (p)\left[\frac{2(1+q)}{1-q}-\frac{2(1-q)}{1+q}\right]\right. \\
& -\exp \left(-P e_{m s} Z\right)\left[\frac{2(1+q)}{p(1-q)+P e_{m s}} \exp (p q)\right. \\
& \left.-\frac{2(1-q)}{p(1+q)+P e_{m s}} \exp (-p q)\right] \\
& -\frac{P e_{m s}}{p} \exp (p Z)\left[\frac{2(1+q) \exp [p q(1-Z)]}{(1-q)\left[p(1-q)+P e_{m s}\right]}\right. \\
& \left.\left.-\frac{2(1-q) \exp [p q(Z-1)]}{(1+q)\left[p(1+q)+P e_{m s}\right]}\right]\right\}
\end{aligned}
$$

where denom. $=(1+q)^{2} \exp (p q)-(1-q)^{2} \exp (-p q)$. When the model is further restricted by assuming ideal plug flow behaviour for both phases, i.e. both $P e_{m g}$ and $P e_{m s}$ approach infinity, the solutions for $x_{g}$ in the gas phase and $x_{s}$ in the solids phase reduce to

$$
x_{g}=1-\exp \left(-N_{m g} Z\right)
$$

and

$$
x_{s}=\frac{N_{m s}}{N_{m g}}\left[\exp \left(-N_{m g} Z\right)-\exp \left(-N_{m g}\right)\right]
$$

\subsection{Numerical solution}

In the non-isothermal case, the complete set of four coupled non-linear second-order differential equations (9)-(12) with the corresponding boundary conditions (14) has to be solved numerically. As has been stated above, the set forms a two-point boundary value problem, because boundary conditions have to be satisfied at $Z=0$ and $Z=1$. In fact, it was solved by solving the dynamic problem expressed by the following set of parabolic partial differential equations:

$$
\begin{aligned}
& \frac{(\varepsilon-\bar{\beta}) L \rho_{g o}}{G} \frac{\partial x_{\theta}}{\partial t}=\frac{1}{P e_{m g}} \frac{\partial^{2} x_{g}}{\partial Z^{2}}-\frac{\partial x_{g}}{\partial Z}+N_{m g}\left(1-x_{g}\right) \\
& \frac{\bar{\beta} L \rho_{s}}{S} \frac{\partial x_{s}}{\partial t}=\frac{1}{P e_{m s}} \frac{\partial^{2} x_{s}}{\partial Z^{2}}+\frac{\partial x_{s}}{\partial Z}+N_{m s}\left(1-x_{\theta}\right) \\
& \frac{(\varepsilon-\bar{\beta}) L \rho_{g o}}{G} \frac{\partial \vartheta_{\theta}}{\partial t}=\frac{1}{P e_{h g}} \frac{\partial^{2} \vartheta_{g}}{\partial Z^{2}}-\frac{\partial \vartheta_{g}}{\partial Z} \\
& -N_{h g}\left(\vartheta_{g}-\vartheta_{s}\right)-N_{h w}\left(\vartheta_{g}-\vartheta_{\text {amb }}\right) \\
& \frac{\bar{\beta} L_{\rho_{s}}}{S} \frac{\partial \vartheta_{s}}{\partial t}=\frac{1}{P e_{h s}} \frac{\partial^{2} \vartheta_{s}}{\partial Z^{2}}+\frac{\partial \vartheta_{s}}{\partial Z} \\
& +N_{h s}\left(\vartheta_{g}-\vartheta_{s}\right)+N_{h r}\left(1-x_{q}\right) \text {. }
\end{aligned}
$$

$x_{g}=1-\exp (p Z)\left\{\frac{2(1+q) \exp [p q(1-Z)]-2(1-q) \exp [p q(Z-1)]}{(1+q)^{2} \exp (p q)-(1-q)^{2} \exp (-p q)}\right\}$ 
From this set of equations, the axial temperature and concentration profiles were calculated numerically as a function of time using a standard library routine D03PBF from the NAG-library (Numerical Algorithms Group, 1979). In this library routine, the "method of lines" is applied to approximate the parabolic equations by a system of ordinary differential equations in time for the values of the four independent variables $\left(x_{\theta}, x_{s}, \vartheta_{g}, \vartheta_{s}\right)$ at mesh points (Sincovec and Madsen, 1975). The space derivatives are approximated by centred finite differences. Since the largest gradients were expected near both $Z=0$ and $Z=1$, the following spacing of the mesh points was chosen:

$$
Z(i)=\frac{1}{2}-\frac{1}{2} \cos [\pi(i-1) /(N-1)]
$$

which clusters the points near both boundaries. In the library routine, the system of ordinary differential equations in time is subsequently integrated using Gear's (1971) backward differentiation method. For the time integration, the initial values of the four independent variables in the mesh points were taken equal to the inlet values (flat profiles). Starting from these flat axial profiles, the time integration was continued until the steady state was reached. This was assumed to be the case when the relative change in the values of the four independent variables in all the mesh points was less than $10^{-6}$ over a time interval of $200 \mathrm{~s}$. Generally, this criterion was fulfilled within 8000 s.

The maximum relative error for the time integration was set at $5 \times 10^{-4}$ for each time step and the chosen number of mesh points was 100 .

Since the numerical solution is time-dependent, it is possible, basically, to use the model to predict the actual dynamic behaviour of the two-phase system. However, in that case several extra terms should be added to the basic model equations, e.g. concerning the heat capacity of the packing and the reactor wall. This was beyond the scope of this study.

\section{FLUE GAS DESULPHURISATION}

The one-dimensional, two-phase axially dispersed plug flow model described above was applied to predict the performance of a full-scale gas-solid trickle flow absorber in a continuous $\mathrm{CuO}$ process for the simultaneous removal of $\mathrm{SO}_{x}$ and $\mathrm{NO}_{x}$ from flue gases. The model computations were focused on flue gas desulphurisation, i.e. the removal of $\mathrm{SO}_{x}$ (especially $\mathrm{SO}_{2}$ ). Realistic values of the various input parameters of the model were obtained from experimental studies on reaction kinetics, hydrodynamics and gas-solids mass transfer data, which were discussed in detail in previous articles (see Section 1). In this section, a brief summary is given of those experimental data that are most relevant with respect to the model computations.

\subsection{Process chemistry and sulphation kinetics}

The main reactions occurring in the absorber and the regenerator of a process for the simultaneous removal of $\mathrm{SO}_{x}$ and $\mathrm{NO}_{x}$ from flue gases using a supported CuO sorbent are given in Table 1.

When flue gas is contacted with the $\mathrm{CuO}$ sorbent in the absorber of the process at a temperature of $300-450^{\circ} \mathrm{C}$, sulphur dioxide $\left(\mathrm{SO}_{2}\right)$ as well as sulphur trioxide $\left(\mathrm{SO}_{3}\right)$ react with the copper oxide $(\mathrm{CuO})$ to form copper sulphate $\left(\mathrm{CuSO}_{4}\right)$. Simultaneously, both $\mathrm{CuO}$ and $\mathrm{CuSO}_{4}$ can act as catalysts for the selective catalytic reduction of nitrogen oxides with ammonia $\left(\mathrm{NH}_{3}\right)$. The (partially) sulphated sorbent can be regenerated at the same temperature level by contacting it with a reducing agent such as hydrogen, carbon monoxide or methane, reducing both $\mathrm{CuO}$ and $\mathrm{CuSO}_{4}$ to metallic copper $(\mathrm{Cu})$. Generally, reoxidation of the regenerated sorbent is carried out in the absorber by the oxygen present in the flue gas (Dautzenberg et al., 1971; Yeh et al., 1985; Stelman et al., 1987).

As stated above, the model computations discussed in this chapter concern the removal of $\mathrm{SO}_{2}$ in a GSTF absorber by sulphation of the $\mathrm{CuO}$ sorbent. The reaction kinetics of this sulphation have been studied extensively in a microbalance reactor (Kiel et al., 1992a) for two supported CuO sorbents, which have been developed at the University of Utrecht (van der Grift, 1990) to meet the requirements set by application of the sorbents in a continuous $\mathrm{CuO}$ process with a GSTF absorber. The two sorbents, called "narrow pore" and "wide pore", referring to their difference in average pore diameter, consisted of a porous spherical silica support manufactured by Shell according to a sol-gel technique (Spek and van Beem, 1982) and $\mathrm{CuO}$ deposited on this support using an ion-exchange technique (Kohler et al., 1987; van der Grift et al., 1990 ) to create a uniform, highly dispersed deposition

Table 1. Process chemistry

\begin{tabular}{cc}
\hline \multicolumn{1}{c}{ Reaction } & $\Delta H^{\circ \dagger}$ \\
\hline Absorber & \\
(1) $2 \mathrm{Cu}+\mathrm{O}_{2} \rightarrow 2 \mathrm{CuO}$ & $-155 \mathrm{~kJ} / \mathrm{mol} \mathrm{Cu}$ \\
(2) $2 \mathrm{CuO}+2 \mathrm{SO}_{2}+\mathrm{O}_{2} \rightarrow 2 \mathrm{CuSO}_{4}$ & $-318 \mathrm{~kJ} / \mathrm{mol} \mathrm{Cu}$ \\
(3) $4 \mathrm{NO}+4 \mathrm{NH}_{3}+\mathrm{O}_{2} \rightarrow 4 \mathrm{~N}_{2}+6 \mathrm{H}_{2} \mathrm{O}$ & $-407 \mathrm{~kJ} / \mathrm{mol} \mathrm{NO}$ \\
Regenerator & $-86.6 \mathrm{~kJ} / \mathrm{mol} \mathrm{Cu}$ \\
(4) $\mathrm{CuO}+\mathrm{II}_{2} \rightarrow \mathrm{Cu}+\mathrm{H}_{2} \mathrm{O}$ & $-10.6 \mathrm{~kJ} / \mathrm{mol} \mathrm{Cu}$ \\
(5) $\mathrm{CuSO}+4 \mathrm{H}_{2} \rightarrow \mathrm{Cu}+\mathrm{SO}_{2}+2 \mathrm{H}_{2} \mathrm{O}$ & $-2 \mathrm{Cu}_{4}$ \\
\hline
\end{tabular}

At $25^{\circ} \mathrm{C}$ (Weast and Astle, 1979). 
Table 2. Properties of the two silica-supported CuO sorbents

\begin{tabular}{|c|c|c|}
\hline Sorbent & $\begin{array}{c}\text { Narrow-pore } \\
\text { np }(5.7)\end{array}$ & $\begin{array}{l}\text { Wide-pore } \\
\text { wp (6.1) }\end{array}$ \\
\hline $\begin{array}{l}\text { Support } \\
\text { Average particle diameter }(\mathrm{mm}) \\
\text { Average pore diameter }(\mathrm{nm}) \\
\text { Pore volume }(\mathrm{ml} / \mathrm{g}) \\
\text { Apparent density of the support }\left(\mathrm{kg} / \mathrm{m}^{3}\right) \\
\text { Cu content ( } \mathrm{wt} \% \text { of oxidised sorbent) }\end{array}$ & $\begin{array}{c}\text { (Shelt-S980A1.5) } \\
1.5 \\
15 \\
1.0 \\
700 \\
5.7\end{array}$ & $\begin{array}{c}\text { (Shell-S980G1.5) } \\
1.5 \\
60 \\
1.0 \\
700 \\
6.1\end{array}$ \\
\hline \multicolumn{3}{|c|}{ 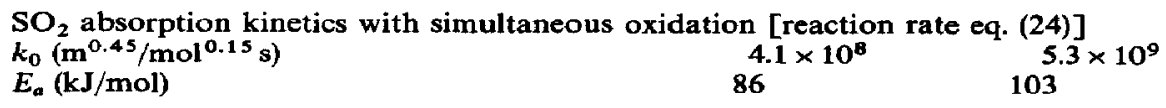 } \\
\hline
\end{tabular}

$5 \mathrm{~kg}$ batches of both sorbents were prepared by Engelhard Co., The Netherlands.

of the $\mathrm{CuO}$ on the internal pore surface. Various properties of both sorbents are listed in Table 2 .

For the narrow-pore sorbent, the kinetic data obtained from the microbalance tests were validated during a series of experiments in a bench-scale plant of the integrated process consisting of a GSTF absorber (length $1.06 \mathrm{~m}$, cross-sectional area $6 \times 6 \mathrm{~cm}^{2}$ ), a fluidised-bed regenerator and a pneumatic transport system for continuous sorbent circulation (Kiel et al., 1990).

The microbalance experiments as well as the benchscale testing clearly revealed that it is very advantageous to contact the regenerated, i.e. reduced, sorbent particles directly with (simulated) flue gas instead of carrying out a separate preoxidation. When reduced sorbent particles containing metallic copper were introduced in the GSTF absorber of the bench-scale plant, oxidation and sulphation occurred simultaneously, the oxidation proceeding much faster than the sulphation. Relatively large $\mathrm{SO}_{2}$ removal degrees were then obtained (up to $50 \%$ of the $\mathrm{SO}_{2}$ in the gas phase was removed over a reactor length of only $1.06 \mathrm{~m}$ ). Apparently, temperature and structural effects caused by the simultaneous occurrence of the exothermic oxidation enhanced the desulphurisation. After completion of the (fast) oxidation, lower $\mathrm{SO}_{2}$ removal degrees (up to $20 \%$ ) were achieved, but they were still considerably higher than when the sorbent particles underwent a separate preoxidation (about 2 times for the wide-pore sorbent and about 5 times for the narrow pore up to a sulphation degree $x_{s}$ of 0.40 ; beyond $x_{s}=0.40$, the sulphation rate in case of simultaneous oxidation rapidly decreased to values even lower than after a separate preoxidation). A separate preoxidation seems to cause a passivation of the $\mathrm{Cu}(\mathrm{O})$ deposits.

In the microbalance, experiments were carried out with simulated flue gas containing $0.05-0.40$ vol. $\%$ $\mathrm{SO}_{2}, 0.5-10$ vol. $\% \mathrm{O}_{2}, 0$ or 15 vol. $\% \mathrm{CO}_{2}, 10$ vol. $\%$ $\mathrm{H}_{2} \mathrm{O}$, and the balance $\mathrm{N}_{2}$. When reduced sorbent particles were contacted directly with this simulated flue gas, the following expression was derived for the intrinsic sulphation rate up to $x_{s}=0.50$, assuming the oxidation of $\mathrm{Cu}$ to $\mathrm{CuO}$ to be completed before sul- phation starts:

$$
r=k_{0} \exp \left(-E_{a} / R T\right) C_{0_{2}^{2}}^{0.15} C_{\mathrm{SO}_{2}}\left(1-1.5 x_{s}\right)
$$

The high sulphation rates during the short oxidation period could not be observed explicitly in the microbalance experiments, because a microbalance allows only a measurement of the weight change of the sample. It could not be distinguished whether the initial weight increase after direct contact of the reduced sorbent with simulated flue gas was due only to the fast oxidation or to a combination of oxidation and sulphation.

Contrary to the case of sulphation after a separate preoxidation, eq. (24) expresses a distinct influence of the oxygen concentration [although $\mathrm{O}_{2}$ was present in (large) excess to $\mathrm{SO}_{2}$ ]. In addition, the decrease of the sulphation rate with increasing sulphation degree $x_{s}$ is stronger than the first-order dependence measured after a separate preoxidation. For both the narrow-pore and the wide-pore ion-exchanged sorbent, the sulphation rate is not influenced by the carbon dioxide concentration in the simulated flue gas. The values of the experimentally determined activation energy, $E_{a}$, and the pre-exponential factor, $k_{0}$, are given in Table 2 . If the intrinsic reaction rate is expressed by eq. (24), then the effective intrinsic reaction rate constant, $k_{r}^{*}$, as applied in the model, becomes

$$
k_{r}^{*}=k_{\mathrm{o}} \exp \left(-E_{a} / R T\right) C_{\mathrm{O}_{2}}^{\mathrm{O} .15}\left(1-1.5 x_{s}\right) .
$$

\subsection{Hydrodynamics}

An important input parameter of the one-dimensional two-phase axially dispersed plug flow model is the average dynamic solids hold-up, $\bar{\beta}$. In the model computations, $\bar{\beta}$-values which have been obtained from a series of hydrodynamic experiments carried out in the bench-scale plant have been applied. For a single packing configuration (see Fig. 1), the average dynamic solids hold-up, $\bar{\beta}$, was determined as a function of the gas and solids mass flux at $375^{\circ} \mathrm{C}$, using unloaded silica particles (the support material of the narrow-pore sorbent; see Table 2 for physical proper- 


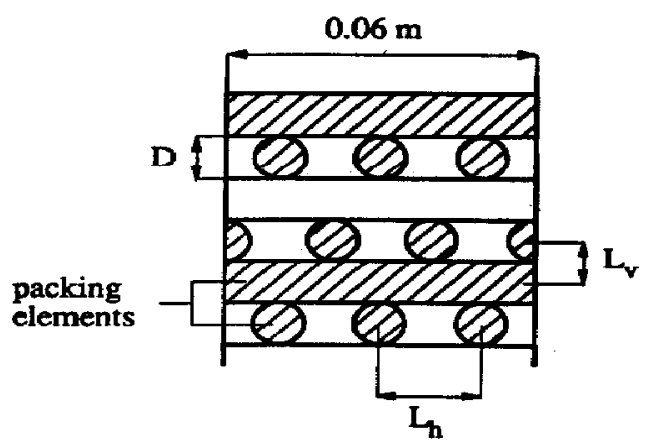

Fig. 1. Packing configuration as applied in the GSTF absorber of the bench-scale plant. Dimensions: packing element diameter $D=10 \mathrm{~mm}$, vertical pitch $L_{v}=10 \mathrm{~mm}$ and horizontal pitch $L_{h}=20 \mathrm{~mm}$. Average packing porosity $\varepsilon=0.607$.

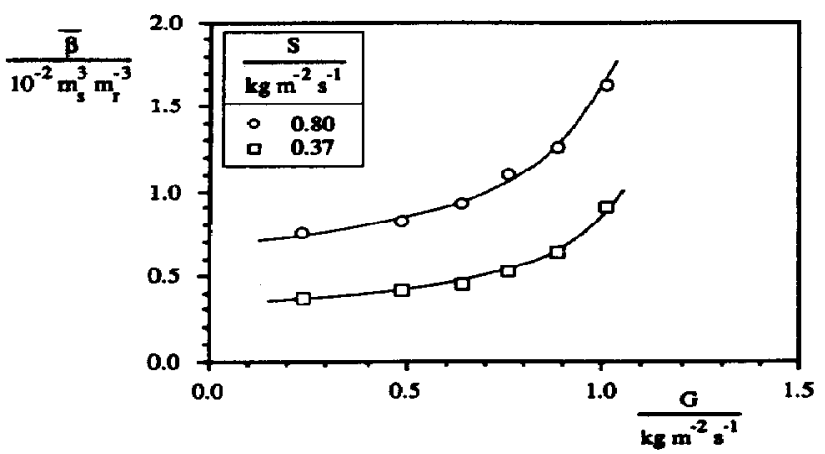

Fig. 2. Average dynamic solids hold-up vs gas mass fux at $375^{\circ} \mathrm{C}$ for two different solids mass fluxes as determined in the bench-scale plant (see Table 3 and Fig. 1), using the unloaded support of the narrow-pore sorbent for the solids phase and nitrogen for the gas phase.

ties) for the solids phase while using nitrogen for the gas phase (see Fig. 2).

Next to the experiments for the unloaded silica particles and nitrogen gas flow, the average dynamic solids hold-up has also been measured in the experiments with actual sorbent material and simulated flue gas. It was found that deviations due to differences in particle and gas density as well as in gas viscosity were within the experimental error of about $10 \%$.

Basically, the average dynamic solids hold-up should not have to be an input parameter of the reactor model, if this model would incorporate the one-dimensional hydrodynamic model presented earlier (Kiel and van Swaaij, 1989). Starting from the separate continuity and momentum equations for both phases, this hydrodynamic model describes the average dynamic solids hold-up and the pressure drop as a function of (i) gas and solids mass flux, (ii) density and viscosity of the gas, (iii) average density and diameter of the solid particles, and (iv) porosity and vertical pitch of the packing. However, for an accurate prediction of the average dynamic solids hold-up (and the pressure drop), proper values of two empirical parameters have to be known a priori, viz. the initial solids velocity $u_{s 0}$ and the hydrodynamic effectiveness factor, $\xi$. The initial solids velocity $u_{s 0}$ is defined as the solids velocity just after the collision of a particle with a packing element, and it accounts for particle-particle interaction during that collision. The hydrodynamic effectiveness factor, $\xi$, is introduced to account for the influence of (i) the axial packing porosity profile, (ii) the radial inhomogeneity of both the gas and solids flow, and (iii) particle shielding on the two-phase flow system. It is defined by the following equation:

$$
u_{g \text { eff }}=\xi \frac{G}{\varepsilon \rho_{g}}
$$

where $u_{g \text { eff }}$ is an effective local gas velocity, which is incorporated in the hydrodynamic model instead of the local gas velocity, $u_{g}\left[=G /\left(\varepsilon \rho_{\theta}\right)\right]$. Generally, both $u_{s o}$ and $\xi$ will not only depend on gas, solids and packing properties but also on the gas and solids mass flux. First attempts were made to derive correlations for these two parameters by comparing calculated hold-up and pressure-drop values with values obtained from experiments at ambient temperature in a $0.10 \times 0.10 \times 0.50 \mathrm{~m}^{3}$ test column. The experiments were carried out for different regularly stacked packings using different sizes of glass beads (average diameter $200-750 \mu \mathrm{m}$ ) for the solids phase, and air for the gas phase. However, the set of experimental data was still too limited to yield correlations for both $u_{\text {so }}$ and $\xi$, which can be applied in a wide range of experimental conditions.

\subsection{Gas-solids heat and mass transfer}

The a verage gas-solids mass transfer coefficient, $k_{a}$, in a GSTF absorber was determined in a series of experiments, in which previously dried molecular sieves were contacted over the packing in the absorber of the bench-scale plant (see Fig. 1) at room temperature, with a nitrogen flow containing $0.6-1.5$ vol. \% water vapour. Despite the rapid adsorption of the water vapour on the molecular sieves, the $\mathrm{H}_{2} \mathrm{O}$ content of the molecular sieves was kept low, because the residence time for the molecular sieves in the absorber was very short (about 1-2 s using a packing length of only $0.27 \mathrm{~m}$ ), and the plant was operated batch-wise without solids recirculation. Therefore, there was only a minor influence of pore diffusion and, consequently, the adsorption rate was predominantly limited by the gas-solids mass transfer (the kinetics of water vapour adsorption on molecular sieves are known to be very fast). $k_{g}$ was calculated from the decrease of the water vapour concentration in the gas phase, assuming (i) plug flow for both phases, (ii) a negligible influence of pore diffusion and (iii) the interfacial area $a$ to be equal to the geometric external surface area of the solids. Two diameter fractions of spherical $4 \hat{\AA}$ molecular sieve particles were used, viz. with an average diameter of 640 and $2200 \mu \mathrm{m}$, respectively. The average gas-solids mass transfer coefficient, $k_{g}$, was found to be about $40-80 \%$ of the value calculated for single 
particles in an undisturbed gas flow, according to the Ranz-Marshall mass transfer correlation (Ranz and Marshall, 1952) expressed as

$$
S h=\frac{k_{g} d_{s}}{D_{A}}=2.0+0.6 R e^{1 / 2} S c^{1 / 3}
$$

with the Reynolds number defined as

$$
R e=\frac{\rho_{g} d_{s}\left|u_{s}-u_{g}\right|}{\mu_{g}} .
$$

In this definition of the Reynolds number, $u_{s}$ and $u_{g}$ represent the average local solids and gas velocities $\left[u_{s}=S /\left(\bar{\beta} \rho_{s}\right)\right.$ and $\left.u_{g}=G /\left(\varepsilon \rho_{g}\right)\right]$. The obtained experimental values were identified as conservative estimates of the actual average gas-solids mass transfer coefficient because the pore diffusion resistance could not be eliminated completely.

From these experimental data on gas-solids mass transfer, and assuming (i) the Chilton-Colburn analogy (Chilton and Colburn, 1934) to be valid (gas-solids heat transfer through convection only; radiation and heat transfer via the packing are neglected) and (ii) the interfacial area $a$ to be equal to the geometric external surface area of the solids, the gas-solids heat transfer coefficient, $\alpha$, is expected to be at least $40-80 \%$ of the value calculated according to the Ranz-Marshall correlation (Ranz and Marshall, 1952) for heat transfer, which may be expressed as

$$
N u=\frac{\alpha d_{s}}{\lambda_{g}}=2.0+0.6 \operatorname{Re}^{1 / 2} \operatorname{Pr}^{1 / 3}
$$

This expectation is supported by experimental findings of Verver and van Swaaij (1986b), who investigated gas-solids heat transfer under trickle flow conditions in a column (cross-sectional area $0.15 \times 0.15 \mathrm{~m}^{2}$ ) containing a regularly stacked packing of bars with a square cross-sectional area of $0.02 \times 0.02 \mathrm{~m}^{2}$. For $370 \mu \mathrm{m}$ sand particles in air, they obtained values of the heat transfer rate constant $\alpha a$, which were about $30-35 \%$ of the ones calculated from the RanzMarshall correlation. The fact that these values are somewhat lower than the $40-80 \%$ mentioned above may be attributed to particle shielding phenomena, which are known to increase with decreasing particle diameter, and which are somewhat more pronounced for the packing applied by Verver and van Swaaij compared to the packing applied in the mass transfer experiments discussed above.

\section{MODEL COMPUTATIONS}

\subsection{Base case conditions}

In Fig. 3, axial profiles are presented of the gas and solids temperature $\left[T_{g}\right.$ and $T_{s} ; \mathrm{Fig}$. 3(a) ], the fractional conversion of $\mathrm{SO}_{2}$ or the $\mathrm{SO}_{2}$ removal degree, and the fractional conversion of $\mathrm{CuO}$ or the sulphation degree $\left[x_{\theta}\right.$ and $x_{s}$, respectively; Fig. $\left.3(b)\right]$ in the GSTF absorber of a full-size flue gas desulphurisation plant, as they were calculated for base case conditions from the one-dimensional axially dispersed plug flow model. The set of base case values for the various input parameters of the model is given in Table 3 . It does not refer to an optimised absorber design; the base case conditions were chosen in such a way that the values of most of the input parameters could be derived from experimental findings. The selection of base case values relies on the following considerations:

- The GSTF absorber is to be operated behind a coal-fired power plant, burning coal with $3 \%$ sulphur, yielding a flue gas composition of 0.2 vol. $\% \mathbf{S O}_{2}, 5$ vol. $\% \mathrm{O}_{2}, 10$ vol. $\% \mathrm{H}_{2} \mathrm{O}, 15$ vol. \% $\mathrm{CO}_{2}$, balance $\mathrm{N}_{2}$ (main components).

- The gas inlet temperature should preferably be in the range of the usual economiser outlet temperatures $\left(325-375^{\circ} \mathrm{C}\right)$, avoiding the necessity of changes in the economiser design.

- The base case incorporates the characteristics of the narrow-pore sorbent, because this sorbent was applied in the bench-scale-plant experiments.

- The applied sulphation kinetics refer to an introduction of completely reduced sorbent particles directly into the absorber. It is assumed that the oxidation is infinitely fast and the intrinsic rate of the subsequent sulphation can be described by
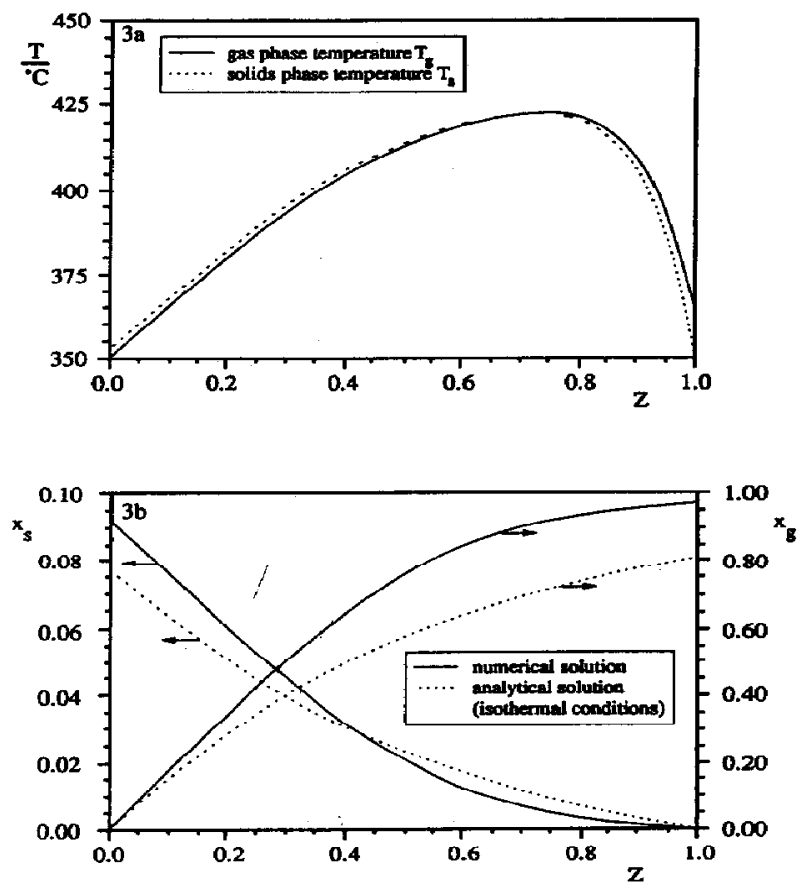

Fig. 3. Axial profiles of the four independent variables $T_{g}, T_{s}, x_{g}$ and $x_{s}$, as calculated numerically for base case conditions listed in Table 3. Also indicated in Fig. 3(b) (dashed lines) are the axial profiles of $x_{q}$ and $x_{a}$, which were calculated from the analytical solution [eqs (16) and (17)] assuming isothermal conditions and the intrinsic reaction rate to be independent of the sulphation degree, $x_{s}$. 
Table 3. Base case values of the input parameters as applied in the model calculations

\begin{tabular}{|c|c|c|}
\hline 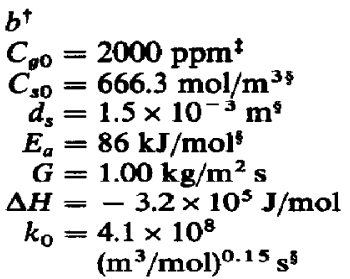 & $\begin{aligned} L & =15 \mathrm{~m} \\
P e_{h g} & =750 \\
P e_{h s} & =750 \\
P e_{m g} & =750 \\
P e_{m s} & =750 \\
S & =0.80 \mathrm{~kg} / \mathrm{m}^{2} \mathrm{~s} \\
T_{g 0} & =623 \mathrm{~K} \\
T_{s 0} & =623 \mathrm{~K}\end{aligned}$ & $\begin{aligned} \alpha_{w} & =0 \mathrm{~W} / \mathrm{m}^{2} \mathrm{~K} \\
\bar{\beta} & =0.0133 \\
\delta & =15 \mathrm{~nm}^{\mathrm{s}} \\
\varepsilon & =0.607 \\
\varepsilon_{s} & =0.70^{s} \\
v & =1 \\
\rho_{s} & =750 \mathrm{~kg} / \mathrm{m}^{38}\end{aligned}$ \\
\hline
\end{tabular}

tThe value of $b$ is irrelevant for adiabatic operation $\left[\alpha_{w}=0 \mathrm{~W} / \mathrm{m}^{2} \mathrm{~K}\right.$; see eq. (3)].

In the model calculations, $C_{g 0}$ in $\mathrm{mol} / \mathrm{m}^{3}$.

sValue corresponding to the narrow-pore sorbent; see Table 2.

eq. (24), with the corresponding values of $k_{0}$ and $E_{a}$ listed in Table 2 (narrow-pore sorbent). Only the heat produced by the sulphation is taken into account.

- The tortuosity factor, $\tau$, is related to the particle porosity, $\varepsilon_{s}$, according to $\tau=1 / \varepsilon_{s}$.

- The gas mass flux, $G$, is taken equal to the highest possible value for the narrow-pore sorbent (see Fig. 2). Higher values of $G$ require sorbent particles with a larger diameter or a higher apparent density.

- According to the experimental data presented in Section 3.2, the average dynamic solids hold-up, $\bar{\beta}$, is approximately directly proportional to the solids mass flux, $S$, at a certain gas mass flux, $G$.

- Heat loss through the reactor wall is neglected. In a full-scale plant, the influence of this heat loss on the thermal performance of the GSTF absorber will be limited as a consequence of a large absorber diameter (about $20 \mathrm{~m}$ for a $600 \mathrm{MW}$ plant).

- Based on the experimental findings discussed in Section 3.3, the values of both the gas-solids heat and mass transfer coefficients are approximated as $50 \%$ of the values calculated from the Ranz-Marshall correlations (Ranz and Marshall, 1952) for a single sphere in an undisturbed gas flow, as expressed by eqs (27)-(29).

- From experimental data presented by Roes and van Swaaij (1979a), it can be estimated that the height of a gas-phase mixing unit will approximately be equal to the height of one to two packing layers at the relatively high superficial gas velocities applied. For the packing shown in Fig. 1 and an absorber length of $15 \mathrm{~m}$, this corresponds to a gas-phase Péclet number of 1500-3000. The chosen value $P e_{g}=750$ may, therefore, be considered as a conservative estimate.

- The solids-phase Péclet number is taken equal to the gas-phase Péclet number, resulting in a value which is roughly in agreement with experimental data presented by Verver and van Swaaij (1986b) for $370 \mu \mathrm{m}$ sand particles and air, flowing at ambient conditions over a regularly stacked packing of bars with a square cross-sectional area of $0.02 \times 0.02 \mathrm{~m}^{2}$.
Furthermore, the correlations listed in Table 4 have been used to calculate the various physical constants.

Figure 3(a) shows a considerable temperature peak for both the phases and a relatively small difference in the local temperature between the two phases. Using the criterion of Anderson (1963), intraparticle temperature gradients were determined to be negligible. $T_{s}$, therefore, represents the uniform temperature of the sorbent particles. The temperature peak is large compared to a gas-phase adiabatic temperature rise of $\Delta T_{a d}=19^{\circ} \mathrm{C}$. It reflects a relatively large accumulation of heat in the reactor, which is due to the occurrence of the exothermic sulphation reaction in combination with efficient counter-current gas-solids heat exchange. For base case conditions, the amount of heat accumulated in the gas and solids phase, defined as the total heat content of both phases in the reactor minus the heat content of the phases at inlet conditions, is equal to the total amount of heat produced by the exothermic sulphation reaction over a period of approximately $9.5 \mathrm{~min}$.

The time required to reach steady-state conditions, i.e. to fulfil the criterion defined in Section 2.3, appeared to be directly related to the magnitude of the temperature peak. Starting from flat profiles at $t=0$, a gradual accumulation of reaction heat, with corresponding changes in the axial profiles of $T_{g}, T_{s}, x_{g}$ and $x_{s}$, occurred in the model computations with the accumulation per time interval gradually decreasing towards zero. In reality, the time required to reach steady-state conditions will be (much) larger than in the model computations due to the large heat capacity of the packing, which was not taken into account in the present model.

The ability to accumulate a considerable amount of reaction heat, i.e. to create an average reactor temperature which is considerably higher than the inlet or outlet temperature of both phases, is, clearly, a beneficial property when applying a GSTFR as an absorber in a $\mathrm{CuO}$ process for flue gas desulphurisation, provided that the maximum temperature remains below $550-600^{\circ} \mathrm{C}$ (the sulphation is prohibited at higher temperatures). In the case of combined removal of $\mathrm{SO}_{x}$ and $\mathrm{NO}_{x}$ by adding $\mathrm{NH}_{3}$ to the flue gas, the temperature peak is also beneficial for $\mathrm{NO}_{x}$ removal, but only up to temperatures of $400-425^{\circ} \mathrm{C}$. A bove this temperature level, a partially sulphated narrow-pore 
Table 4. Correlations for the physical constants as applied in the model calculations

$$
\begin{aligned}
& c_{p g}^{\dagger}=1.037 \times 10^{3}+0.161 T_{g}+18.95 \times 10^{-6}\left(T_{g}\right)^{2}-5.471 \times 10^{6} /\left(T_{\theta}\right)^{2} \\
& c_{p s}^{\ddagger}=0.732 \times 10^{3}+0.647 T_{s}-1.613 \times 10^{7} /\left(T_{s}\right)^{2} \\
& D_{\text {s.ll }}^{\text {s. }}=0.0110 \times 10^{-3}\left(T_{s} / 273\right)^{1.75}\left(0.1013 \times 10^{6} / P\right) \\
& \lambda_{g}=0.0478\left(T_{a} / 670\right)^{0.75} \\
& \mu_{g}^{\dagger+}=-6.25 \times 10^{-6}+0.0840 \times 10^{-6} T_{g}-0.0381 \times 10^{-9} /\left(T_{g}\right)^{2} \\
& \rho_{g}^{6}=1.332\left(273 / T_{g}\right)\left(P / 0.1013 \times 10^{6}\right)
\end{aligned}
$$

${ }^{\dagger}$ Perry and Green (1984); based on a flue gas composition of $5 \% \mathrm{O}_{2}$, $10 \% \mathrm{H}_{2} \mathrm{O}, 15 \% \mathrm{CO}_{2}$ and balance $\mathrm{N}_{2}$ (main components).

\$Valid up to $847 \mathrm{~K}$, data for $\alpha$-quortz (Barin and Knacke, 1973).

Based on a flue gas composition of $5 \% \mathrm{O}_{2}, 10 \% \mathrm{H}_{2} \mathrm{O}, 15 \% \mathrm{CO}_{2}$ and balance $\mathrm{N}_{2}$ (main components).

"According to Blanc's law (Blanc, 1908), with the binary diffusion coefficients estimated from the correlation of Fuller et al. (1966).

TValid for $T_{g}=573-873 \mathrm{~K}$, based on the data for air at atmospheric pressure (Weast and Astle, 1979).

${ }^{+}$Valid for $T_{g}=500-900 \mathrm{~K}$, based on the data for air at atmospheric pressure (Weast and Astle, 1979).

sorbent starts to lose its selectivity towards the catalytic reduction of $\mathrm{NO}$ by $\mathrm{NH}_{3}$, and the direct oxidation of $\mathrm{NH}_{3}$ by the $\mathrm{O}_{2}$ present in the flue gas becomes the prevailing reaction. Because of the large influence of the gas-phase and solids-phase temperature profiles on the $\mathrm{SO}_{x}$ and $\mathrm{NO}_{x}$ removal degrees, they have been calculated as a function of various input parameters. The results are reported and discussed in Section 4.2.

The considerable accumulation of heat in the GSTF absorber calculated numerically is clearly the main cause of the differences between (i) the axial profiles of the $\mathrm{SO}_{2}$ removal degree, $x_{g}$, and the sulphation degree, $x_{s}$, calculated from the numerical model and (ii) the ones calculated from the analytical solution assuming isothermal conditions and the intrinsic reaction rate to be independent of the fractional conversion of $\mathrm{CuO}$ [Fig. 3(b)]. Due to the resulting increased temperature level, the numerically calculated values of $x_{g}$ and consequently, also of $x_{x}$ are higher than the ones calculated analytically, even though the analytical solution does not contain the decreasing effect of an increase of $x_{s}$ on the intrinsic reaction rate.

To check whether the assumption of a uniform sulphation degree inside the sorbent particles is valid for the two sorbents considered, the effectiveness factor, $\eta$, is shown for both of them as a function of particle temperature in Fig. 4. Especially in the case of the narrow-pore sorbent, the influence of pore diffusion in the temperature range of interest $\left(350-400^{\circ} \mathrm{C}\right)$ appears to be considerable. Due to the pore diffusion resistance, a concentration gradient for $\mathrm{SO}_{2}$ will occur inside the sorbent particles during their fall through the GSTF absorber. Consequently, a radial gradient for the sulphation degree, $x_{s}$, inside the particles will gradually be built up ( $x_{s}$ decreasing towards the particle centre). An accurate prediction of the desulphurisation performance of the GSTF absorber would, therefore, actually require a model in which an account is taken of this radial gradient in sulphation degree inside the sorbent particles.

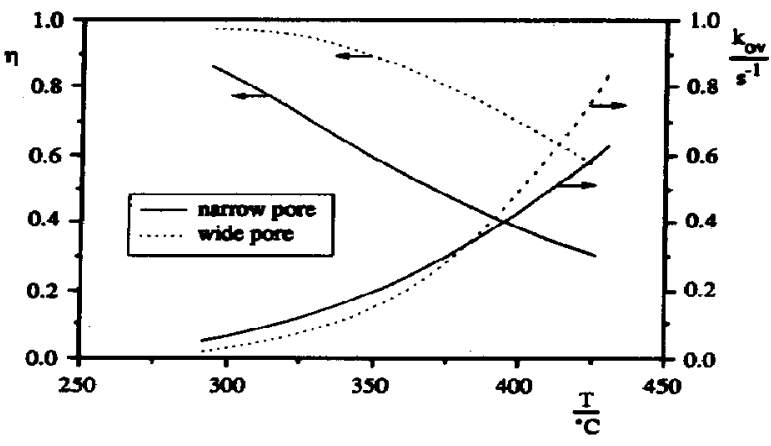

Fig. 4. Effectiveness factor, $\eta$, and overall (sulphation) rate constant $k_{o v}$ vs temperature $T$ for both the narrow-pore and wide-pore sorbent. Equation (25) was applied for the effective intrinsic reaction rate constant, $k_{r}^{*}$, with $\mathrm{CO}_{2}$ equivalent to 5 vol. $\%$ and $x_{s}=0$, and eq. (7) for the effective diffusion coefficient, $D_{\text {eff }}$. The gas-solids mass transfer rate constant, $k_{p} a$, was calculated for base case inlet conditions taking $k_{\mathrm{g}}$ equal to $50 \%$ of the value calculated from the RanzMarshall correlation [eq. (27)].

Moreover, the relatively low sulphation degree per pass $\left[x_{s} \approx 0.09\right.$ for base case conditions, see Fig. 3(b)] may also necessitate a more complex model. Namely, this low sulphation degree per pass does not seem to favour an operating mode in which the sorbent particles are regenerated after each pass, because then a relatively large amount of reducing agent would have to be used to reduce the unsulphated $\mathrm{CuO}$ to $\mathrm{Cu}$. Although the introduction of reduced sorbent particles in the absorber causes very high sulphation rates as a result of the simultaneous oxidation (see Section 3.1), it is probably preferable from an economic point of view to minimise the consumption of reducing agent by recirculating the sorbent particles to the GSTF absorber for several times until an average sulphation degree of $x_{s}=0.30-0.50$ is reached. Higher average $x_{s}$-values are not desirable because they result in a very low sulphation rate. The absorber will then be fed with a mixture of sorbent particles, part of them 
in the reduced state with a very high initial $\mathrm{SO}_{2}$ removal activity, and others with various different initial sulphation degrees and, consequently, a lower activity. An accurate prediction of the flue gas desulphurisation performance of a GSTF absorber in a CuO process would then require a modelling approach in which (i) the high (intrinsic) sulphation rate during in situ oxidation, (ii) the heat production resulting from the exothermic oxidation, and (iii) a certain initial distribution of the sulphation degree, $x_{s}$, are taken into account explicitly.

Despite the limitations of the present model, however, it can be applied quite well to obtain a first approximation of the performance of a GSTF absorber in a $\mathrm{CuO}$ process for flue gas desulphurisation, and to clarify the influence of various input parameters on this performance.

The larger influence of the pore diffusion resistance for the narrow-pore sorbent if compared to the widepore sorbent does not imply automatically that the narrow-pore sorbent is the less effective one. This is illustrated in Fig. 4, showing the overall sulphation rate constant, $k_{o v}$ [see eq. (8)] vs temperature for both sorbents. Since the gas-solids mass transfer resistance is very small, $k_{o v}$ mainly reflects the combined resistance of pore diffusion and reaction kinetics (for base case conditions, $T=350^{\circ} \mathrm{C}$ and $x_{s}=0$, $\left(k_{g} a\right)^{-1}=0.078 \mathrm{~s}$ and $\left.\left(\bar{\beta} k_{r}^{*} \eta\right)^{-1}=5.06 \mathrm{~s}\right)$. Up to $380^{\circ} \mathrm{C}$, the lower value of the effectiveness factor, $h$, for the narrow-pore sorbent, if compared to the widepore sorbent, is outweighed by the higher value of the effective reaction rate constant $k_{r}^{*}$. Thus, up to this temperature, the narrow-pore sorbent is even more effective than the wide-pore sorbent. At higher temperatures, the wide-pore sorbent becomes more effective due to a stronger increase of $k_{r}^{*}$ with temperature (see Table 2) combined with the smaller pore diffusion resistance.

\subsection{Influence of different input parameters on the per-} formance of a GSTF absorber in a CuO process for fue gas desulphurisation

In this section, attention will be focused mainly on the most striking effect appearing in the computations for base case conditions, viz. the considerable accumulation of heat, resulting in a considerable temperature peak in the reactor. One of the parameters influencing the magnitude of this temperature peak is the gas-solids heat transfer coefficient, $\alpha$. This is illustrated in Fig. 5, which shows calculated axial temperature profiles in both phases for two values of $\alpha$. From the analogy between convective heat and mass transfer (see Section 3.3), the value of the gas-solids mass transfer coefficient, $k_{\theta}$, was adjusted correspondingly. However, the variations in $k_{g}$-values have a negligible influence on the overall rate constant $k_{o v}$, because the gas-solids mass transfer resistance is very small compared to the combined resistance of pore diffusion and sulphation kinetics (see Section 4.1).

According to Fig. 5, the maximum temperature of both the phases in the reactor increases with increas-

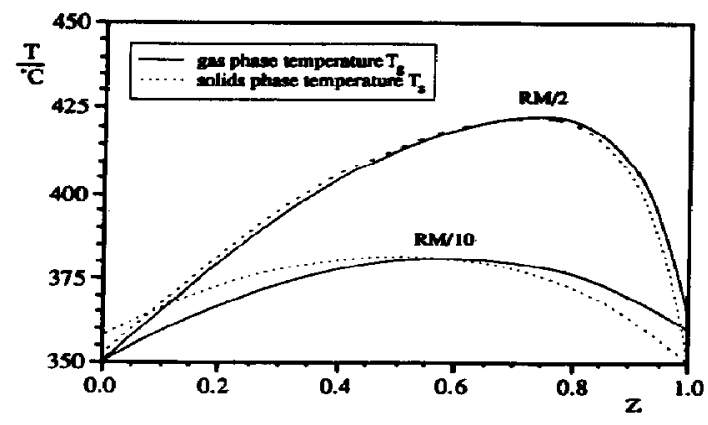

Fig. 5. Computed axial profiles of the gas and solids temperature for $\alpha=\alpha_{R M} / 2$ and $k_{\theta}=k_{g R M} / 2$, and for $\alpha=\alpha_{R M} / 10$ and $k_{g}=k_{g R M} / 10$, with $\alpha_{R M}$ and $k_{g R M}$ calculated from the Ranz-Marshall correlations for the gas-solids heat and mass transfer coefficients in the case of a single sphere in an undisturbed gas flow. Values of other input parameters of the numerical model are listed in Table 3.

ing $\alpha$ while at the same time, as to be expected, the average absolute temperature difference between both phases $\left|T_{s}-T_{g}\right|$ decreases. The influence of $\alpha$ on the amount of heat accumulated in the reactor can be understood by considering the gas-solid trickle flow reactor as a packed column consisting of three sections, viz. two heat-exchange sections at the top and the bottom with a reaction section in between. Sorbent particles entering the reaction section increase in temperature due to the exothermic sulphation reaction. In the lower heat-exchange section, part of the heat accumulated in the solids phase is transferred to the upward-flowing gas phase. The heated gas flows through the reaction section to the upper heat-exchange section, where part of the heat accumulated in the gas phase is transferred to the downwardflowing sorbent phase again. In this way, reaction heat is circulated inside the reactor. At an increasing heat transfer coefficient, $\alpha$, the gas-solids heatexchange efficiency increases. Relatively large temperature gradients will then have to be built up near both reactor outlets (corresponding to a relatively large temperature peak in the reactor) to achieve temperature differences between both phases at the reactor outlets, which are sufficiently large to enable the removal of all the heat produced by the sulphation reaction (this condition has to be fulfilled in the case of steady-state conditions and no heat transfer through the reactor wall).

A second important parameter, influencing not only the magnitude of the temperature peak but also the axial position of the maximum gas and solids temperature, is the heat capacity ratio of both phases, $F_{h}$, defined as

$$
F_{h}=\frac{S c_{p s}}{G c_{p q}}
$$

This is illustrated in Fig. 6(a)-(c). In these figures, reactor performance is shown for various values of the solids mass flux, $S$ (at a constant value of the gas mass flux, $G$ ) instead of $F_{h}$, because $F_{h}$ varies slightly over the reactor length due to the temperature dependence 

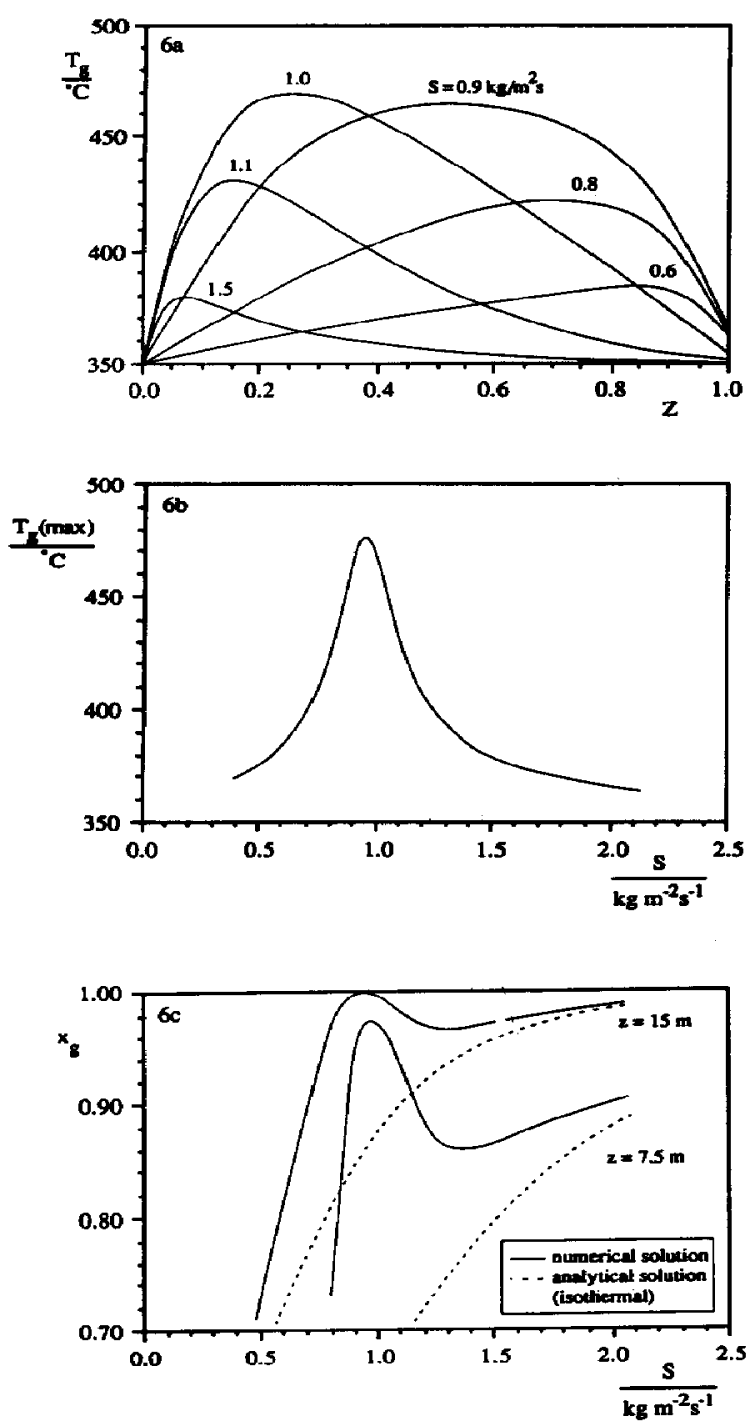

Fig. 6. Influence of the solids mass flux, $S$, on (a) the axial temperature profile for the gas phase, (b) the maximum gas-phase temperature in the absorber and (c) the $\mathrm{SO}_{2}$ removal degree $x_{0}$ in the middle of the reactor $(z=7.5 \mathrm{~m})$ and at the gas outlet $(z=15 \mathrm{~m})$, as calculated from both the numerical model and the analytical solution. Values of other input parameters are listed in Table 3.

of the specific heat capacities $c_{p s}$ and $c_{p g}$ (see Table 4). Moreover, since the temperature difference between both phases is rather small due to the high gas-solids heat transfer rates, only gas-phase temperatures are presented.

The influence of $S$ (or $F_{h}$ ) on the magnitude and axial position of the temperature peak is clearly shown in Fig. 6(a). The highest temperature peak, with its maximum in the middle of the reactor, occurs for $S \approx 0.95 \mathrm{~kg} / \mathrm{m}^{2} \mathrm{~s}$, which corresponds to $F_{h} \approx 1$. At $S>0.95 \mathrm{~kg} / \mathrm{m}^{2} \mathrm{~s}\left(F_{h}>1\right)$, the magnitude of the temperature peak decreases and its maximum moves towards the bottom of the reactor, while at $S<0.95 \mathrm{~kg} / \mathrm{m}^{2} \mathrm{~s}\left(F_{h}<1\right)$, the magnitude of the tem-
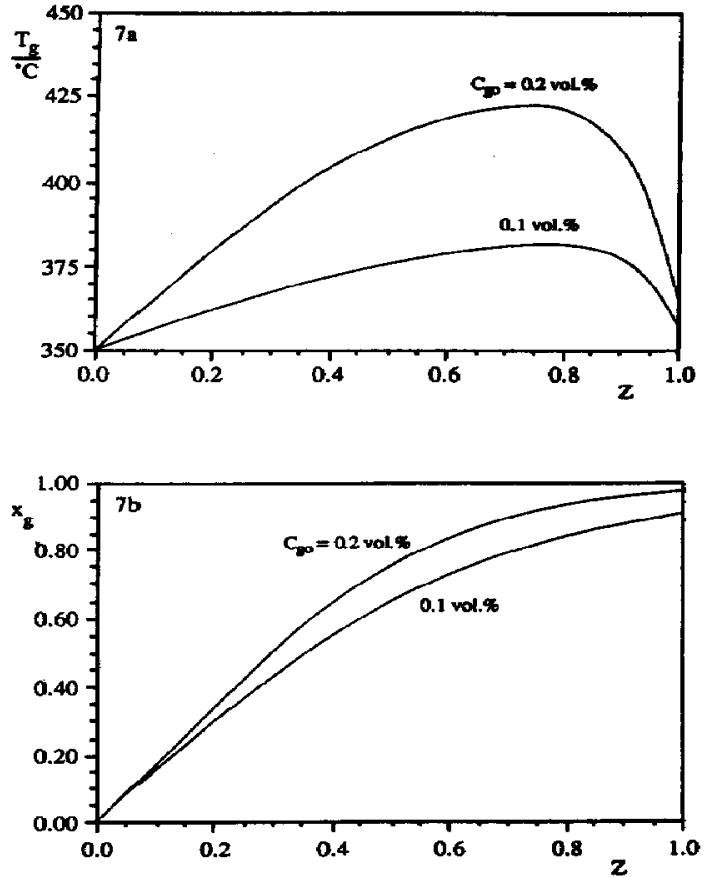

Fig. 7. (a) Computed axial profiles of the gas-phase temperature, $T_{g}$ and (b) the $\mathrm{SO}_{2}$ removal degree $x_{g}$ for two different $\mathrm{SO}_{2}$ inlet concentrations $C_{00}$. Values of other input parameters of the numerical model are listed in Table 3.

perature peak also decreases but its maximum then moves towards the top of the reactor. From Fig. 6(b), showing the maximum gas temperature, $T_{g}(\max )$, vs the solids mass flux, $S$, it can be seen that a considerable accumulation of heat in the reactor occurs only for $S$-values in a limited range around $S \approx 0.95 \mathrm{~kg} / \mathrm{m}^{2}$ s, i.e. for $F_{h}$-values close to $F_{h}=1$. The beneficial effect of the (solids-phase) temperature peak on the $\mathrm{SO}_{2}$ removal degree $x_{g}$ as a function of $S$ (or $F_{h}$ ) is shown in Fig. 6(c) by comparing $x_{g}$-values calculated from the numerical model to values obtained from the analytical solution (assuming isothermal conditions and the intrinsic reaction rate to be independent of the sulphation degree, $x_{s}$ ) for various $S$-values.

Obviously, the magnitude of the temperature peak depends on the specific heat production rate, i.e. on the reaction enthalpy, $\Delta H$, the $\mathrm{SO}_{2}$ concentration at the gas inlet, $C_{g o}$ and the overall rate constant, $k_{o v}$. With respect to $C_{\theta 0}$, this is confirmed by Fig. 7, which illustrates the influence of $C_{80}$ on the temperature effect. The maximum gas-phase temperature appears to be approximately directly proportional to $C_{g 0}$.

Also heat loss through the reactor wall may influence the magnitude of the temperature peak. This is shown in Fig. 8, in which the effect of heat loss through the reactor wall in combination with heat production by exothermic sulphation on the axial gas-phase temperature profile is presented for base case conditions (Table 3). The reactor is assumed to 


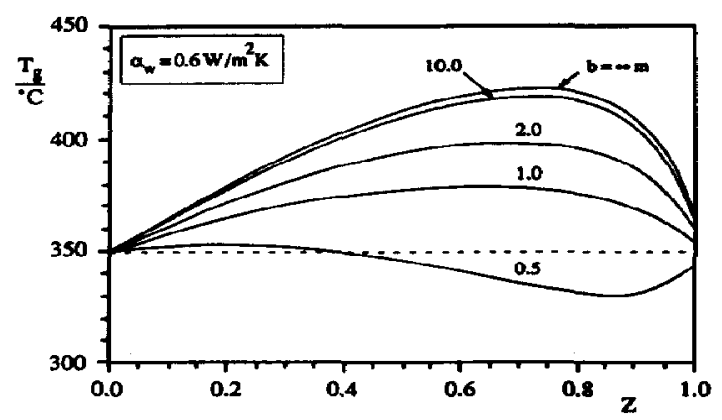

Fig. 8. Axial profile of the gas-phase temperature, $T_{\theta}$, for different reactor widths, $b$. In the model computations, $\alpha_{w}=0.6 \mathrm{~W} / \mathrm{m}^{2} \mathrm{~K}$, while base case values listed in Table 3 were chosen for the other input parameters.

be insulated with $10 \mathrm{~cm}$ rockwool $\left(\lambda_{s}=0.06 \mathrm{~W} / \mathrm{m} \mathrm{K}\right)$, resulting in an overall heat transfer coefficient $\alpha_{w}=0.6 \mathrm{~W} / \mathrm{m}^{2} \mathrm{~K}$, the conduction of heat through the insulating material being the rate-determining step. From Fig. 8, the heat loss through the reactor wall appears to be negligible in the case of a full-scale GSTF absorber $(b=10-20 \mathrm{~m})$; the gas-phase ternperature profile is hardly affected. For reactor widths down to $0.5 \mathrm{~m}$, however, the temperature peak decreases considerably. For $b=0.5 \mathrm{~m}$, a (small) temperature increase occurs only in the lower part of the reactor $(0<Z<0.4)$; in the upper part of the reactor $(0.4<Z<1.0)$, a decrease in temperature occurs. Apparently, for $b=0.5 \mathrm{~m}$ the heat loss through the reactor wall per unit reactor length is of the same order of magnitude as the heat production per unit reactor length. Since the latter decreases with increasing $Z$ due to a decreasing $\mathrm{SO}_{2}$ concentration, this results in a net heat production for $0<Z<0.4$ and a net heat loss for $0.4<Z<1.0$.

The influence of axial dispersion in both phases is shown in Fig. 9. It appears that the base case $P e$-value $(P e=750)$ virtually corresponds to plug flow behaviour, since a further increase in the $P e$-value up to $P e=7500$ only has a very small effect on the axial profiles of $T_{y}$ and $x_{y}$. However, a considerable deviation from plug flow behaviour occurs already for $P e=75$ [often $P e=20$ may still be regarded as a reasonable approach to plug flow, Westerterp et al. (1984)]. Due to the increased axial mixing, the heat accumulated becomes better distributed over the reactor, resulting in a lower temperature maximum and a slightly lower $\mathrm{SO}_{2}$ removal degree at the gas outlet.

Finally, Fig. 10 shows the gas-phase temperature, $T_{g}$, and the $\mathrm{SO}_{2}$ removal degree, $x_{g}$, as a function of $Z$ for different values of the total reactor length, $L$. Clearly, the maximum gas-phase temperature decreases with decreasing $L$. This is caused by two effects. First, the total amount of heat produced in the reactor decreases with decreasing $L$, corresponding to a decreasing $x_{g}$ at the gas outlet of the reactor [see Fig. 10(b)]. Secondly, the gas-solids heat-exchange efficiency (or capacity) decreases with decreasing $L$, resulting in a decreased circulation or accumulation
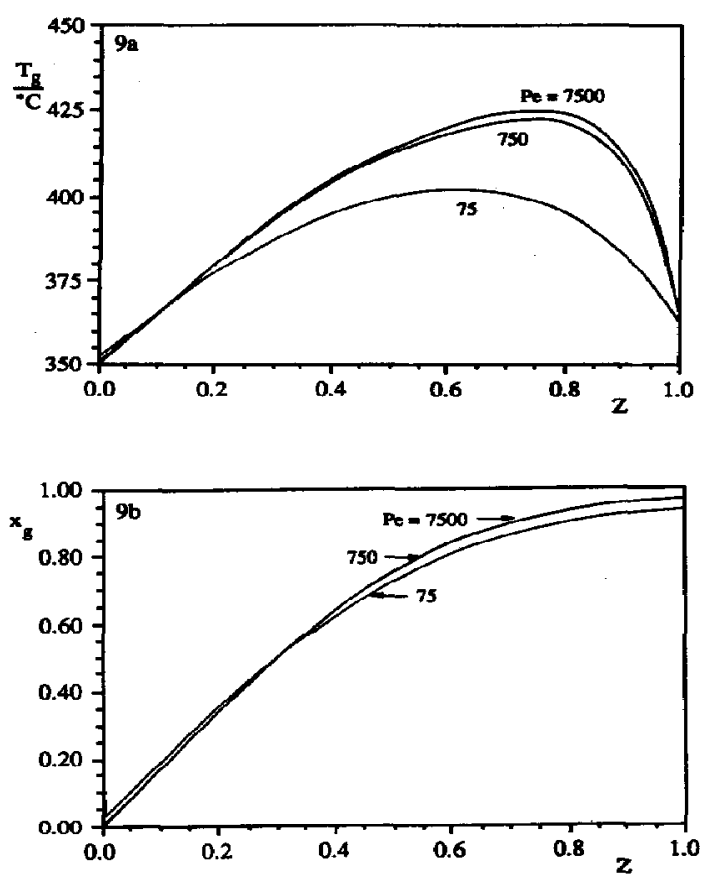

Fig. 9. (a) Computed axial profiles of the gas-phase temperature, $T_{a}$ and (b) the $\mathrm{SO}_{2}$ removal degree, $x_{a}$ for different values of the Péclet number, assuming $P e_{m a}=$ $P e_{m s}=P e_{h g}=P e_{h s}=P e$. Values of other input parameters of the numerical model are listed in Table 3.
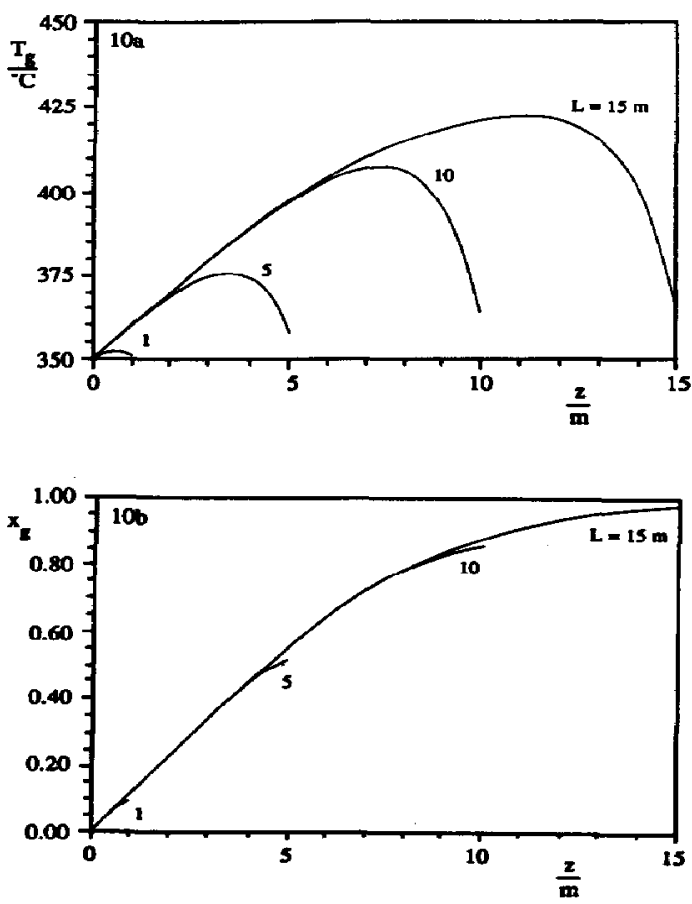

Fig. 10. (a) Computed axial profiles of the gas-phase temperature, $T_{g}$ and (b) the $\mathrm{SO}_{2}$ removal degree, $x_{0}$ for different reactor lengths, $L$. Values of other input parameters of the numerical model are listed in Table 3. 
of heat (the "number of transfer units" decreases). Figure 10 clearly illustrates why the remarkable temperature effect was not observed in the GSTF absorber of the bench-scale plant having a length of only $1.06 \mathrm{~m}$. In practice, the heat accumulated for $L=10,5$ and $1 \mathrm{~m}$ may be better distributed over the reactor, even resulting in a lower temperature maximum than shown in Fig. 10, because in the model computations the Péclet number was kept constant while in reality it will be directly proportional to $L$.

\section{CONCLUSIONS}

A one-dimensional, two-phase axially dispersed plug flow model has been derived from the separate mass and heat balances to describe the steady-state performance of a gas-solid trickle flow reactor (GSTFR) for the case of a non-catalytic gas-solid reaction, which is first-order in the gaseous reactant. The reaction rate was also allowed to depend on the solid reactant concentration, but this concentration was assumed to be low and constant throughout the solids volume.

The model was applied to predict the flue gas desulphurisation performance of a full-scale GSTF absorber in a dry, regenerative process for the simultaneous removal of $\mathrm{SO}_{x}$ and $\mathrm{NO}_{x}$ from flue gases. In this process, to be operated at $350-400^{\circ} \mathrm{C}$, the sorbent material consists of a porous silica support (spherical particles $1.5 \mathrm{~mm}$ diameter) with about $7.5 \mathrm{wt} \% \mathrm{CuO}$ deposited on this support through an ion-exchange technique. Axial profiles of the four independent variables, viz. the gas- and solids-phase temperatures and the concentrations of $\mathrm{SO}_{2}$ and $\mathrm{CuO}$, were calculated numerically for "base case" conditions, which were selected based on experimental findings from previous studies regarding reaction kinetics, hydrodynamics of the two-phase flow, gas-solids mass transfer and testing of the integrated process in a bench-scale plant.

It appeared that $\mathrm{SO}_{2}$ removal efficiencies over $95 \%$ can be achieved in a GSTF absorber with a length of $15 \mathrm{~m}$. Typical operation conditions are: a gas mass flux $G=1 \mathrm{~kg} / \mathrm{m}^{2} \mathrm{~s}$ (the maximum allowable value for which counter-current operation is maintained when applying the $1.5 \mathrm{~mm}$ diameter silica-supported sorbents), a solids mass flux of $0.8 \mathrm{~kg} / \mathrm{m}^{2} \mathrm{~s}$ and a gas and solids inlet temperature of $350^{\circ} \mathrm{C}$.

Moreover, the numerical calculations revealed a considerable temperature peak for both the phases inside the absorber, provided that the heat capacity ratio, $F_{h}$, is close to one. $F_{h}$ is defined as the ratio of solids mass flux times specific heat capacity of the solids over gas mass flux times specific heat capacity of the gas. This temperature peak is due to the occurrence of the exothermic sulphation reaction in combination with efficient counter-current gas-solids heat exchange. The highest temperature peak, with its maximum in the middle of the GSTF absorber, occurs for $F_{h}=1$. At $F_{h}>1$, the magnitude of the temperature peak decreases and its maximum moves to- wards the bottom of the absorber, while at $F_{h}<1$, the magnitude of the temperature peak also decreases but its maximum then moves towards the top of the absorber.

At a fixed value of $F_{h}$, the magnitude of the temperature peak decreases at a decreasing net specific heat production rate, i.e. at a decrease of the reaction heat. the $\mathrm{SO}_{2}$ (inlet) concentration or the overall rate constant, or at an increase of the specific heat loss through the absorber wall. In addition, the magnitude of the temperature peak decreases at a decreasing gas-solids heat-exchange efficiency, i.e. at a decrease of the gas-solids heat transfer coefficient or the absorber length.

\section{NOTATION}

$a$

b

$c_{p}$

$C_{g}$

$C_{\text {s }}$

$d_{s}$

$D_{l}$

$D_{A}$

$D_{\text {eff }}$

$D_{K}$

$E_{a}$

$F_{h}$

G

$\Delta \boldsymbol{H}^{\circ}$

$\boldsymbol{k}_{\boldsymbol{g}}$

$k_{0}$

$k_{\text {ov }}$

$k_{r}^{*}$

L

M

p

$P$

$q$

$r$

$R$

$S$

$\boldsymbol{t}$

$T$

$\Delta T_{a d}$

u

$u_{\text {geff }}$

$u_{s 0}$

U

$x$

$z$

$Z$ specific interfacial area, $\mathrm{m}^{-1}$

reactor width, $m$

heat capacity per unit mass, at constant pressure, $\mathrm{J} \mathrm{kg}^{-1} \mathrm{~K}^{-1}$

concentration of gaseous reactant, $\mathrm{mol} \mathrm{m}^{-3}$ concentration of solid reactant, $\mathrm{mol} \mathrm{m}^{-3}$

average particle diameter, $m$ coefficient of longitudinal dispersion, $\mathrm{m}^{2} \mathrm{~s}^{-1}$ molecular diffusion coefficient, $\mathrm{m}^{2} \mathrm{~s}^{-1}$

effective pore diffusion coefficient, $\mathrm{m}^{2} \mathrm{~s}^{-1}$ Knudsen diffusion coefficient, $\mathrm{m}^{2} \mathrm{~s}^{-1}$

activation energy, $\mathbf{J} \mathrm{mol}^{-1}$

heat capacity ratio $\left(=S c_{p s} / G c_{p s}\right)$, dimensionless

gas mass flux, $\mathrm{kg} \mathrm{m}^{-2} \mathrm{~s}^{-1}$

reaction enthalpy at $25^{\circ} \mathrm{C}, \mathrm{J} \mathrm{mol}^{-1}$

gas-solids mass transfer coefficient, $\mathrm{m} \mathrm{s}^{-1}$

frequency factor of the intrinsic reaction rate constant [see eq. (24)], $\mathrm{m}^{0.45} \mathrm{~mol}^{-0.13} \mathrm{~s}^{-1}$ overall rate constant [see eq. (8)], $\mathrm{s}^{-1}$

effective intrinsic reaction rate constant, including the influence of the solid reactant conversion and the $\mathrm{O}_{2}$ concentration [see eq. (25)], $s^{-1}$

reactor or packing length, $m$

molar mass, $\mathrm{kg} \mathrm{mol}^{-1}$

parameter in eqs (15) and (16), dimensionless pressure, $\mathbf{P a}$

parameter in eqs (15) and (16), dimensionless intrinsic reaction rate, $\mathrm{mol} \mathrm{m}^{-3} \mathrm{~s}^{-1}$

gas constant, $\mathrm{J} \mathrm{mol}^{-1} \mathrm{~K}^{-1}$

solids mass flux, $\mathrm{kg} \mathrm{m}^{-2} \mathrm{~s}^{-1}$

time, $s$

temperature, $\mathrm{K}$

adiabatic temperature rise, $K$

local velocity, $\mathrm{m} \mathrm{s}^{-1}$

effective local gas velocity [see eq. (26)], $\mathrm{ms} \mathrm{s}^{-1}$

initial solids velocity, $\mathrm{ms}^{-1}$

superficial velocity, $\mathrm{m} \mathrm{s}^{-1}$

fractional conversion of reactant, dimensionless

axial coordinate, $\mathrm{m}$

dimensionless axial coordinate $(=z / L)$, dimensionless 


\section{Greek letters}

$\alpha$

$\bar{\beta}$

$\boldsymbol{\delta}$

$\varepsilon$

E.

n

Q

$\lambda$

$\lambda_{\boldsymbol{l}}$

$\mu$

$\boldsymbol{v}$

$\xi$

$\rho$

$\tau$

$\phi$

\section{Subscripts}

amb ambient conditions

calc calculated

exp experimental

$g$ gas-phase quantities

$h$ heat balance

$i \quad$ conditions at the gas-solids interface

$m$ mass balance

$p \quad$ packing quantities

$r$ reactor dimension, reaction

$s \quad$ solids-phase quantities

$w$ reactor wall

0 inlet or initial conditions

\section{Dimensionless groups}

$N \quad$ dimensionless group, see eq. (13)

$\mathrm{Nu} \quad$ Nusselt number $\left(=\propto d_{s} / \lambda_{g}\right)$

$\mathrm{Pe} \quad$ Péclet number, see eq. (13)

$\operatorname{Pr} \quad$ Prandtl number $\left(=\mu_{g} c_{p g} / \lambda_{g}\right)$

Re particle Reyuolds number $\left(=\rho_{q} d_{s} \mid u_{s}-\right.$ $\left.u_{g} \mid / \mu_{g}\right)$

Sc Schmidt number $\left(=\mu_{g} / \rho_{g} D_{A}\right)$

Sh particle Sherwood number $\left(=k_{g} d_{s} / D_{A}\right)$

\section{REFERENCES}

Anderson, J. B., 1963, A criterion for isothermal behaviour of a catalyst pellet. Chem. Engng Sci. 18, 147.

Barin, I. and Knacke, O., 1973, Thermochemical Properties of Inorganic Substances. Springer, Berlin.

Blanc, A., 1908, J. Phys. 7, 825.

Chilton, T. H. and Colburn, A. P., 1934, Mass transfer (absorption) coefficients. Ind. Engng Chem. 26, 1183.

Danckwerts, P. V., 1953, Continuous flow systems. Chem. Engng Sci. 2, 1.

Dautzenberg, F. M., Naber, J. E. and van Ginneken, A. J. J., 1971, Shell's flue gas desulfurization process. Chem. Engng Prog. 67(8), 86.

Froment, G. F. and Bischoff, K. B., 1979, Chemical Reactor Analysis and Design. Wiley, New York.
Fuller, E. N., Schettler, P. D. and Giddings, J. C., 1966, Ind. Engng Chem. 58(5), 18.

Gear, C. W., 1971, Numerical Initial Value Problems in Ordinary Differential Equations. Prentice-Hall, Englewood Cliffs, NJ.

Guigon, P., Large, J. F. and Molodtsof, Y., 1986, Hydrodynamics of raining packed bed heat exchangers, in Encyclopedia of fluid mechanics (Edited by N. P. Cheremisinoff), Vol. 4, Chap. 39. Gulf, Houston, TX.

Kiel, J. H. A. and van Swaaij, W. P. M., 1989, A theoretical model for the hydrodynamics of gas-solid trickle flow over regularly stacked packings. A.I.Ch.E. Symp. Ser. 85(270), 11.

Kiel, J. H. A., Prins, W. and van Swaaij, W. P. M., 1990, Flue gas desulphurization in a gas-solid trickle flow reactor with a regenerable sorbent, in Proceedings of Process Technology: Gas Separation Technology (Edited by E. F. Vansant and R. Dewolfs), Vol. 8, pp. 539-548. Elsevier, Amsterdam.

Kiel, J. H. A., 1990, Removal of sulphur oxides and nitrogen oxides from flue gas in a gas-solid trickle flow reactor. Ph.D. thesis, University of Twente, Enschede.

Kiel, J. H. A., Prins, W. and van Swaaij, W. P. M., 1992a, Performance of silica-supported copper oxide sorbents for $\mathrm{SO}_{x} / \mathrm{NO}_{x}$-removal from flue gas: I. Sulphur dioxide absorption and regeneration kinetics. Appl. Catal. B Envir. 1, 13.

Kiel, J. H. A., Edelaar, A. C. S., Prins, W. and van Swaaij, W. P. M., 1992b, Performance of silica-supported copper oxide sorbents for $\mathrm{SO}_{x} / \mathrm{NO}_{x}$-removal from flue gas: II. Selective catalytic reduction of nitric oxide by ammonia. Appl. Catal. B Envir. 1, 41.

Kohler, M. A., Lee, J. C., Trimm, D. L., Cant, N. W. and Wainwright, M. S., 1987, Preparation of $\mathrm{Cu} / \mathrm{SiO}_{2}$ catalysts by the ion-exchange technique. Appl. Catal. 31, 309.

Kuczynski, M., 1986, The synthesis, of methanol in a gas-solid-solid trickle flow reactor. Ph.D. thesis, University of Twente, Enschede.

Large, J. F., Guigon, P. and Saatdjian, E., 1983, Multistaging and solids distributor effects in a raining packed bed exchanger, in Proceedings of the 4th International Conference on Fluidization. Kashikojima, Japan.

Numerical Algorithms Group, 1979, NAG FORTRAN LIBRARY, MARK II, Vol. 2. Oxford.

Perry, R. H. and Green, D. W., 1984, Perry's Chemical Engineers' Handbook, 6th Edition. McGraw-Hill, New York.

Ploeg, J. E. G., 1981, A process for the simultaneous removal of nitrogen oxides and sulphur oxides from a gas stream. European patent EP $0024061 \mathrm{A1}$.

Ranz, W. E. and Marshall, W. R., 1952, Evaporation from drops. Chem. Engng Prog. 48(3), 141 (Part I) and 48(4), 173 (Part II).

Roes, A. W. M. and van Swaaij, W. P. M., 1979a, Axial dispersion of gas and solid phases in a gas-solid packed column at trickle flow. Chem. Engng J. 18, 13.

Roes, A. W. M. and van Swaaij, W. P. M., 1979b, Mass transfer in a gas-solid packed column at trickle flow. Chem. Engng J. 18, 29.

Satterfield, C. N., 1970, Mass Transfer in Heterogeneous Catalysis. MIT Press, Cambridge, MA.

Sincovec, R. M. and Madsen, N. K., 1975, Software for nonlinear partial differential equations. A.C.M. Trans. Math. Software 1, 232.

Spek, T. G. and van Beem, M. J. L., 1982, Silica particles and method for their preparation. European patent EP 0067459 A1.

Stelman, D., Ampaya, J. P. and Newcomb, J. C., 1987, Simultaneous removal of $\mathbf{N O}_{x}, \mathbf{S O}_{x}$, and particulates from flue gas by a moving bed of copper oxide. Report DOE contract DE-AC22-83PC60262.

van der Grift, C. J. G., 1990, On the development of copperbased sorbents for flue gas desulfurization. Ph.D. thesis, University of Utrecht, The Netherlands. 
van der Grift, C. J. G., Mulder, A. and Geus, J. W., 1990, Characterization of silica-supported copper catalysts by means of temperature-programmed reduction. Appl. Catal. 60, 181.

Vernon, J. L., 1988, Emission standards for coal-fired plants: air pollution control policies. Report IEACR-11, IEA Coal Research, London.

Verver, A. B. and van Swaaij, W. P. M., 1986a, The hydrodynamic behaviour of gas-solid trickle flow over a regularly stacked packing. Powder Technol. 45, 119.

Verver, A. B. and van Swaaij. W. P. M., 1986b. The heattransfer performance of gas-solid trickle flow over a regularly stacked packing. Powder Technol. 45, 133.
Verver, A. B. and van Swaaij, W. P. M., 1987, The gas-solid trickle-flow reactor for the catalytic oxidation of hydrogen sulphide: a trickle-phase model. Chem. Engng Sci. 42, 435.

Weast, R. C. and Astle, M. J., 1979, CRC Handbook of Chemistry and Physics. CRC Press, Boca Raton, FL.

Wehner, J. F. and Wilhelm, R. H., 1956, Boundary conditions of flow reactor. Chem. Engng Sci. 6, 89.

Westerterp, K. R., van Swaaij, W. P. M. and Beenackers, A. A. C. M., 1984, Chemical Reactor Design and Operation. Wiley, New York.

Yeh, J. T., Demski, R. J., Strakey, J. P. and Joubert, J. I., 1985, Combined $\mathrm{SO}_{2} / \mathrm{NO}_{x}$ removal from flue gas. Environ. Prog. 4, 223. 